\title{
Application of failure mode and effect analysis to tomotherapy treatment delivery
}

\author{
S. Broggi ${ }^{1}$, M.C. Cantone ${ }^{2 \star}$, A. Chiara ${ }^{3}$, N. Di Muzio ${ }^{3}$, B. Longobardi ${ }^{1}$, P. Mangili $^{1}$ and I. Veronese $^{2}$ \\ ${ }^{1}$ Servizio di Fisica Sanitaria, Ospedale San Raffaele, 20132 Milano, Italy. \\ 2 Dipartimento di Fisica, Università degli Studi di Milano, 20122 Milano, Italy. \\ 3 Servizio di Radioterapia, Ospedale San Raffaele, 20132 Milano, Italy.
}

Received 1st April 2015 - Accepted 22 June 2015

\begin{abstract}
The failure mode and effect analysis (FMEA) approach was used to assess the potential risks for patients during the delivery of tomotherapy treatments. This study, which completed a previous investigation recently performed on the tomotherapy pretreatment phases, enabled the delineation of the delivery process tree and the identification of 30 failure modes, 9 of which were judged to be of particular concern. Novel solutions and strategies for dealing with these failures are accordingly proposed, and addressed both to the clinical staff directly involved in the delivery process, and to the machine vendor.
\end{abstract}

Keywords: FMEA / Tomotherapy / Risk Assessment / Radiotherapy

\section{Introduction}

Helical tomotherapy was developed at the University of Wisconsin more than twenty years ago, with the purpose of integrating an intensity-modulated radiotherapy (IMRT) machine with a highly image-guided system, useful to verify the setup of the patient just before the treatment delivery (Mackie et al. 1993, 1999). Currently, more than 280 tomotherapy treatment centers are available worldwide and, among the approximately 80 centers in European countries, most of them are located in France and Italy ${ }^{1}$.

The intrinsic complexity of a tomotherapy treatment, as well as of other types of IMRT-based processes, places new demands on innovative approaches to patient safety. Proactive methods of risk analysis, aiming to anticipate the potential hazards that may occur during the RT process, are particularly fit to investigate the risks of this clinical practice. In this scenario, failure mode and effect analysis (FMEA), routinely employed in high-risk industries, is an emerging and effective tool recommended by the International Commission on Radiological Protection (ICRP, 2009) and the American Association of Physicists in Medicine (AAPM) (Huq et al., 2008). Nowadays, FMEA is recognized as a powerful and increasingly popular tool for proactive risk analysis in modern radiation oncology (Ford et al. 2009; Ciocca et al., 2012; Perks et al., 2012; Cantone et al., 2013; Begnozzi et al., 2014; Ford et al., 2014; Masini et al., 2014; Veronese et al., 2015).

\footnotetext{
* marie.cantone@unimi.it

1 http://www.accuray.com/treatment-centers
}

In a recent study, the FMEA approach was applied to the pretreatment phases of the tomotherapy process implemented at the San Raffaele Scientific Institute (Broggi et al., 2013). The results of this investigation allowed the improvement of the local safety measures with the adoption of novel solutions for dealing with the failures of greatest concern in terms of overall risk or severity of the consequences. The above study was also used as a reference for the improvement of a novel rapid tomotherapy-based radiation therapy workflow (Jones et al., 2014). The present work aims to complete the FMEA analysis of the tomotherapy process, focusing the attention on the delivery stage that, together with the planning and treatment information transfer stages, was recognized to be one of the most critical steps in a general radiation therapy (RT) workflow (WHO, 2008).

\section{Materials and methods}

The same working group (WG) established for the FMEA analysis recently performed on the simulation, imaging, volume determination and treatment planning stages of the tomotherapy process was involved in the risk analysis of the delivery stage. Three medical physicists, two radiation oncologists, and two external physicists with experience and competence in radiation protection and risk management strategies for radiotherapy composed the core of the WG. In addition, radiation therapy technologists, i.e. the staff mainly involved in the delivery stage, actively contributed to the discussions and analyses. 


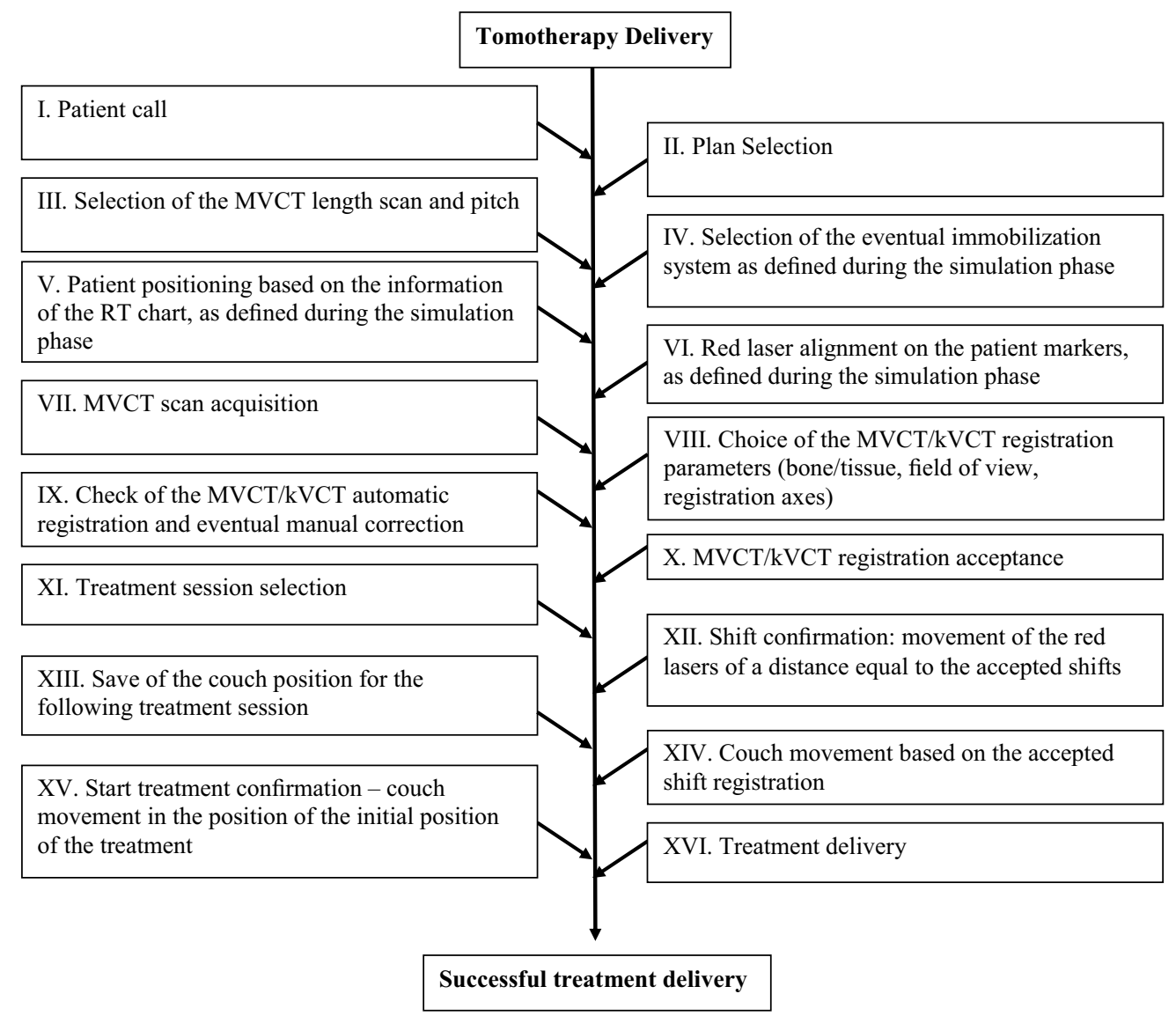

Figure 1. Sub-processes of the delivery stage in tomotherapy treatment. In cases of treatment interruption (system crash), after generation of the completion procedure and patient repositioning in the starting position, start again from step XV.

The outcomes of the WG meetings were: (i) the delineation of the process tree of the delivery stage; (ii) the identification and ranking of the potential failure modes, together with their causes and effects, and (iii) the identification of additional safety measures to be proposed for process quality and safety improvement.

The ranking of the failure modes was carried out by using the risk probability number (RPN) system, each RPN being obtained as a product of three indices: the occurrence rate $(\mathrm{O})$, the severity rate (S) and the detectability rate (D). A ten-point scale was used to score each category, ten being the number indicating the most severe, most frequent and least detectable failure mode, respectively. The strategies and solutions currently applied at the San Raffaele Scientific Institute to mitigate the risk in the routine clinical practice, as well as the quality assurance practices and protocols (Broggi et al., 2008), were taken into account for the assessment of the risk indices.

\section{Results and discussion}

The delivery stage of the tomotherapy process was modeled with 16 sub-processes, starting from patient call, up to treatment delivery. The complete process tree is shown in Figure 1. A total of 30 failure modes were identified; nine of them were judged to be of particular concern (RPN > 80). These failures, together with their causes, potential effects, risk in- dices and RPN values are summarized in Table 1 and discussed below.

The first failure was identified during the patient call, and consisted of incorrect patient identification. The most severe potential consequence could be the treatment of the wrong patient for a single session, possible in cases where the anatomical site to be treated was the same as that of the correct patient, and in cases where the Mega-Volt Computed Tomography (MVCT) scan performed before treatment delivery (i.e. the safety measure currently adopted) did not allow the failure detection. The WG decided to improve the safety measures with the introduction of the patient's picture in the database, and the practice of verifying the patient's identity by the radiation therapist letting the patient him/herself state personal information (i.e. name and birth date) immediately after entering the treatment area.

The introduction of the patient's picture is already used in our clinical practice for patients treated with conventional Linac; therefore, its introduction also for patients treated with helical tomotherapy units should be of simple implementation, without an excessive increase in the workload. For patients treated with conventional Linac the patient's picture is taken during the verification of treatment plans with a conventional simulator; this phase is not present in the tomotherapy planning/delivery process; a more appropriate phase should therefore be defined. The introduction of these safety measures 
Table 1. FMEA of the the stage of delivery. Failures with RPN $\geqslant 80$ are shown.

\begin{tabular}{|c|c|c|c|c|c|c|c|c|}
\hline Sub-process & $\mathbf{N}$ & Potential failure mode & Potential causes of failure & Potential effects of failure & $\mathbf{S}$ & $\mathbf{O}$ & D & RPN \\
\hline \multirow[t]{4}{*}{ I. Patient call } & 1 & $\begin{array}{l}\text { Wrong patient } \\
\text { identification (with } \\
\text { the same anatomical } \\
\text { site) }\end{array}$ & Lack of attention & $\begin{array}{l}\text { Wrong treatment for } \\
\text { a single session }\end{array}$ & 7 & 2 & 6 & 84 \\
\hline & 2 & $\begin{array}{l}\text { Delivery of a single } \\
\text { procedure and not } \\
\text { "double procedure" } \\
\text { in cases where the } \\
\text { daily dose (hypo- } \\
\text { fractionation schedule) } \\
\text { cannot be delivered in } \\
\text { a single procedure }\end{array}$ & $\begin{array}{l}\text { Lack of attention } \\
\text { and/or inadequate } \\
\text { RT chart } \\
\text { compilation }\end{array}$ & $\begin{array}{l}\text { Wrong dose delivery for } \\
\text { several fractions. Impact } \\
\text { on the radiobiological } \\
\text { effect }\end{array}$ & 8 & 3 & 7 & 168 \\
\hline & 3 & $\begin{array}{l}\text { Delivery of a single } \\
\text { procedure and not } \\
\text { "double procedure" } \\
\text { in cases where the } \\
\text { daily dose (hypo- } \\
\text { fractionation } \\
\text { schedule) cannot be } \\
\text { delivered in a single } \\
\text { procedure }\end{array}$ & $\begin{array}{l}\text { Lack of attention } \\
\text { and/or inadequate } \\
\text { RT chart } \\
\text { compilation }\end{array}$ & $\begin{array}{l}\text { Wrong daily dose } \\
\text { delivery. Impact on the } \\
\text { radiobiological effect }\end{array}$ & 5 & 3 & 7 & 105 \\
\hline & 4 & $\begin{array}{l}\text { Plan selection of } \\
\text { the wrong patient } \\
\text { (same anatomical } \\
\text { site but not yet } \\
\text { treated) }\end{array}$ & Lack of attention & $\begin{array}{l}\text { Wrong treatment for } \\
\text { a single session }\end{array}$ & 7 & 2 & 6 & 84 \\
\hline $\begin{array}{l}\text { VIII. Choice of } \\
\text { the kVCT/MVCT } \\
\text { registration } \\
\text { parameters } \\
\text { (registration axis) }\end{array}$ & 5 & $\begin{array}{l}\mathrm{kVCT} / \mathrm{MVCT} \\
\text { automatic } \\
\text { registration in } 6 \\
\text { directions (and } \\
\text { not in 4) }\end{array}$ & $\begin{array}{l}\text { Lack of attention } \\
\text { and/or inadequate } \\
\text { skill }\end{array}$ & $\begin{array}{l}\text { Wrong patient } \\
\text { positioning/alignment and } \\
\text { not correspondent to the } \\
\text { visible and approved } \\
\text { kVCT/MVCT matching. }\end{array}$ & 4 & 4 & 8 & 128 \\
\hline $\begin{array}{l}\text { IX. Check of the } \\
\text { kVCT/MVCT } \\
\text { automatic } \\
\text { registration and } \\
\text { eventual manual } \\
\text { correction }\end{array}$ & 6 & $\begin{array}{l}\text { Wrong } \\
\mathrm{kVCT} / \mathrm{MVCT} \\
\text { matching }\end{array}$ & Inadequate skill & $\begin{array}{l}\text { Wrong patient } \\
\text { positioning/alignment, } \\
\text { wrong dose delivery }\end{array}$ & 5 & 4 & 9 & 180 \\
\hline $\begin{array}{l}\mathrm{X} . \mathrm{kVCT} / \mathrm{MVCT} \\
\text { registration } \\
\text { acceptance }\end{array}$ & 7 & $\begin{array}{l}\text { The "Accept" } \\
\text { option is not } \\
\text { selected on the } \\
\text { treatment console }\end{array}$ & $\begin{array}{l}\text { Lack of attention } \\
\text { and/or inadequate } \\
\text { skill }\end{array}$ & $\begin{array}{l}\text { Loss of all the information } \\
\text { concerning the } \\
\text { registration, inadequate } \\
\text { treatment }\end{array}$ & 4 & 4 & 8 & 128 \\
\hline $\begin{array}{l}\text { XIV. Couch } \\
\text { movement based } \\
\text { on accepted shift } \\
\text { registration }\end{array}$ & 8 & $\begin{array}{l}\text { "Setup" button not } \\
\text { pressed, no couch } \\
\text { movement }\end{array}$ & Lack of attention & $\begin{array}{l}\text { Inadequate daily } \\
\text { delivered dose }\end{array}$ & 4 & 4 & 8 & 128 \\
\hline $\begin{array}{l}\text { XVI. Treatment } \\
\text { delivery }\end{array}$ & 9 & $\begin{array}{l}\text { Temporary } \\
\text { treatment delivery } \\
\text { interruption with } \\
\text { the possibility of } \\
\text { completing the } \\
\text { procedure }\end{array}$ & $\begin{array}{l}\text { Tomotherapy unit } \\
\text { interruption/crash }\end{array}$ & $\begin{array}{l}\text { Wrong patient } \\
\text { repositioning with } \\
\text { the consequent wrong } \\
\text { dose delivery }\end{array}$ & 8 & 4 & 6 & 192 \\
\hline
\end{tabular}


should decrease the detectability rate (D) as well as the occurrence rate $(\mathrm{O})$.

The second and third failures, occurring during the plan selection, concerned the so-called "double procedure". According to this treatment strategy, the daily dose is delivered in two consecutive runs if a single irradiation cannot be performed. This could be the case of very high hypofractionated schedules where because of mechanical limits, the high dose cannot be delivered in a single procedure. The consequences of delivering a single procedure instead of the double one may be particularly severe in cases where this failure is repeated for several fractions, and less important if it occurs in only one session. A written warning message on the RT chart, clearly indicating the need for the "double procedure", is the safety measure currently adopted. Therefore, the correct RT chart compilation, together with a systematic double check should contribute to mitigating the risk of these failures.

RT chart double checks have been used in our clinical practice since 1995. An independent control of the monitor units (MU) and dose distribution calculation, together with a check of the data reported in the treatment chart, was reported as an effective tool in greatly reducing the occurrence of systematic errors before treatment delivery (Calandrino et al., 1997). This good practice will still be implemented in our departments after the introduction of the Record and Verify system.

Based on this experience, the double check was also introduced in the tomotherapy workflow with the aim of reducing the occurrence rate $(\mathrm{O})$.

However, considering their high RPN values, the WG stressed the need for a Record and Verify system integrated in the tomotherapy database. The lack of this integration was already pointed out during the previous FMEA study on the pretreatment phases. In fact, the implementation of such a system may significantly contribute to improving the patient safety during the whole tomotherapy process. In addition, the possibility of inserting on-line messages to the radiation therapist before the MVCT acquisition and/or before treatment delivery should be considered. The introduction of this safety measure should decrease or even reduce to zero the possibility of delivering the wrong session dose.

Another potential failure recognized during the step of plan selection was the selection of the plan of the wrong patient, with the same anatomical site to be treated, but not yet treated or not scheduled for the same day (failure N4 in Table 1). If this failure is not detected by the MVCT scan acquisition, the wrong treatment for a single session may occur. The introduction of the patient's picture in the database, as previously suggested, represents a valuable safety measure for increasing the detectability of this failure.

The fifth failure of high concern identified by the WG, potentially occurring during the choice of the kVCT/MVCT registration parameters (registration axes), consisted of automatic registration in six directions, despite the fact only four directions can actually be corrected. In such cases, the wrong treatment can be delivered as a consequence of the wrong patient positioning. A specific strategy to deal with this failure is not currently implemented in the RT workflow. The most effective safety measure, according to the WG analysis, was the implementation, by the vendor, of a warning message in the software of the machine concerning the need for yaw and pitch manual correction, when these directions were included in the registration process.

The following sub-processes in the delivery workflow, i.e. checking the correctness of the automatic $\mathrm{kVCT} / \mathrm{MVCT}$ registration parameters with possible manual correction, and the acceptance of such registration, were also prone to critical failures (N6 and 7 in Table 1). Indeed, the adoption of a wrong $\mathrm{kVCT} / \mathrm{MVCT}$ matching led to incorrect patient positioning and thus to a delivered dose that was different from the planned one. Similarly, in cases where the radiation therapist does not accept the shifts, as approved by the radiation oncologist (i.e. does not select the "accept" option at the treatment console and ignores the related software warning message), all the information concerning the registration can be lost. Another subprocess proved to be essential for the correct patient positioning, and therefore for an accurate dose delivery: the movement of the couch based on the accepted shift registration. In order to perform such a movement, the "setup" button must be pressed at the treatment console. Since these last two failures (N7 and 8 in Table 1) may occur as a consequence of a lack of attention, and/or inadequate skill of the staff involved in the delivery stage, the WG stressed the importance of improving all the factors contributing to the competence, awareness and concentration of the radiation therapist dealing with the workflow. In fact, the establishment of dedicated training schemes on the operations and limits of the tools and software employed in the delivery process, as well as on the related procedures and protocols, may drastically contribute to reducing the frequency of failures and, consequently, the overall risk of accidents. Moreover, excessive workload and haste should be avoided, and the work environment should encourage working with awareness, avoid distractions and facilitate concentration.

Finally, a major failure (N9 in Table 1) potentially occurring in the last step of the RT process consists of a temporary delivery interruption due to the machine crashing. In such cases, the wrong repositioning of the patient may lead to an incorrect treatment. The detection of this failure, currently possible thanks to the video check of the patient, can be further improved by the systematic checking and annotation of the initial longitudinal couch position. This was already implemented in our clinical practice from the beginning without an excessive workload; the initial couch position is one of the pieces of data that the radiation therapy technologists should annotate in the RT chart. It is important to underline that in cases where this initial position is wrongly annotated or there are any other doubts, the radiation treatment could be correctly recovered after the repetition of a MVCT scan; this option allows the delivery of a correct treatment, also if the treatment session time slightly increases. This safety measure allows one to reduce the occurrence rate to zero.

All the changes proposed try to reduce the error risk, modifying the value of the occurrence rate, and as a consequence diminishing the total RPN value. Using pictures of patients is the only safety measure that is able to reduce not only the occurrence rate but also the detectability rate.

Most of the proposed process changes have been implemented in our routine without an excessive workload; moreover, we think that they could reduce the operator stress 
because all these actions increase the safety of the delivery process.

The application of FMEA to radiation treatments should take over the more critical aspects for patient safety. Based on this kind of analysis arising from the user's clinical experience, the vendors should implement appropriate upgrades.

\section{Conclusions}

The FMEA approach was applied to the delivery stage of a typical tomotherapy treatment implemented at the San Raffaele Scientific Institute. This study, which completed a previous analysis carried out on the pretreatment phases, confirmed the strengths and limitations of this proactive method for risk analysis. The results enabled the identification of additional safety measures that may contribute to improving the patient safety. These new solutions are addressed both to the clinical staff routinely involved in the treatment delivery stage, as well as to the vendor, through the implementation of new software solutions and warnings.

\section{References}

Begnozzi L. et al. (2014) Prospective approaches for risk analysis in modern radiotherapy: the Italian experience and the contribution of the medical physicists, Radioprotection 49, 43-47.

Broggi S. et al. (2008) Results of a two-year quality control program for helical tomotherapy unit, Radiot. Oncol. 86, 231-241.

Broggi S. et al. (2013) Application of failure mode and effects analysis (FMEA) to pretreatment phases in tomotherapy, J. Appl. Clin. Med. Phys. 14, 265-277.

Calandrino R. et al. (1997) Detection of systematic errors in external radiotherapy before treatment delivery, Radiother. Oncol. 45, 271-274.
Cantone M.C. et al. (2013) Application of failure mode and effects analysis to treatment planning in scanner proton beam radiotherapy, Radiat. Oncol. 8,127.

Ciocca M. et al. (2012) Application of failure mode and effect analysis to intraoperative radiation therapy using mobile electron linear accelerators, Int. J. Radiat. Oncol. Biol. Phys. 21, e305-e311.

Ford E.C. et al. (2009) Evaluation of safety in a radiation oncology setting using failure mode and effects analysis, Int. J. Radiat. Oncol. Biol. Phys. 74, 852-858.

Ford E.C. et al. (2014) A streamlined failure mode and effects analysis, Med. Phys. 41, 061709.

Huq M.S. et al. (2008) A method for evaluating quality assurance needs in radiation therapy, Int. J. Radiat. Oncol. Biol. Phys. 71, S170-S173.

ICRP Publication 112 (2009) Preventing Accidental Exposures from New External Beam Radiation Therapy Technologies. Ann. ICRP 39.

Jones R.T. et al. (2015) Safety and feasibility of STAT RAD: Improvement of a novel rapid tomotherapy-based radiation therapy workflow by failure mode and effects analysis, Pract. Radiat. Oncol. 5, 106-112.

Mackie T.R. et al. (1993) Tomotherapy: a new concept for the delivery of dynamic conformal, Med. Phys. 20, 1709-1719.

Mackie T.R. et al. (1999) Tomotherapy, Semin. Radiat. Oncol. 9, 108117.

Masini L. et al. (2014) Application of failure mode and effects analysis to intracranial stereotactic radiation surgery by linear accelerator, Pract. Radiat. Oncol. 4, 392-297.

Perks J.R. et al. (2012) Failure mode and effect analysis for delivery of lung stereotactic body radiation therapy, Int. J. Radiat. Oncol. Biol. Phys. 83, 1324-1329.

Veronese I. et al. (2015) Multi-institutional application of Failure Mode and Effects Analysis (FMEA) to CyberKnife Stereotactic Body Radiation Therapy (SBRT), Radiat. Oncol. 10, 132.

WHO (2008) Radiotherapy Risk Profile. World Health Organization Press, Geneva. 